\title{
Effect of moderate intensity noise exposure on the cochlea of adult male guinea pig and the possible protective role of Pravastatin: Histological study
}

\section{Original Article}

\author{
Suzy I. Hanfy, Hany K. K. Mostafa, Azza Abd El Moneim and Hend I. Farid \\ Department of Histology and Cell Biology, Faculty of Medicine, Ain Shams University, Cairo, \\ Egypt
}

\begin{abstract}
Introduction: Noise induced hearing loss, which is the second most common type of sensorineural hearing loss after presbycusis, is an irreversible disorder but potentially preventable. Extensive studies have documented the damaging effects of high intensity acoustic overexposures on the cochlea, but only few works have focused on the danger of overexposure to moderate intensity noise. Statins recently attracted more attention due to their pleotropic effects.

Aim: To evaluate the structural changes in the cochlea of adult male guinea pigs exposed to moderate intensity noise and to assess the possible protective role of Pravastatin.

Materials and Methods: Twenty four adult male guinea pigs were included. They were divided into three groups. Group I: served as a control group. Group II: animals were exposed to noise 70-90 dB 6 hours/day for 6 wk. Group III: animals were exposed to noise for the same duration and received Pravastatin $20 \mathrm{mg} / \mathrm{kg} /$ day once daily from the $1 \mathrm{st}$ day of exposure for 6 weeks.

Results: Light and scanning electron microscopic examination of the cochleae of group II revealed that noise exposure resulted in extensive degrees of damage to the hair cells, their stereocilia, stria vascularis and spiral ganglia. Administration of Pravastatin resulted in improvement of the cochlear structures compared to the noise exposed group. Morphometric and statistical study confirmed the previous results.

Conclusion: Pravastatin daily administration during exposure to moderate intensity noise showed protective effects on the cochlear structure of guinea pig.
\end{abstract}

Key Words: Cochlea, guinea pig, noise, pravastatin.

Revised: 26 April 2017, Accepted: 17 August 2017

Corresponding Author: Hany K. K. Mostafa, Tel: 01120388467, Email:mennahany15@yahoo.com, Department of Histology and Cell Biology, Faculty of Medicine, Ain Shams University, Cairo, Egypt

ISSN:1110-0559, September 2017, Vol. 40, No. 3

\section{INTRODUCTION}

Hearing impairment is a rapidly growing healthcare issue worldwide, which has a profound impact on an individual's quality of life. Hence, a significant effort has been made to understand the pathophysiological mechanisms of noise-induced cell death in the cochlea as well as to develop interventions in order to reduce or prevent noise induced hearing loss (NIHL).

Most of these studies extensively documented the damaging effects of high intensity acoustic overexposures on the cochlea, while only few researches were conducted to evaluate the dangers of moderate intensity noise overexposure which is a common problem nowadays ${ }^{[1,2]}$.

So far, there is no effective treatment for NIHL. The target organ of noise is cochlea in the inner ear, where sensory hair cells are affected by noise through some possible mechanisms including mechanical, metabolic, and vascular mechanisms ${ }^{[3,4]}$.Therefore, antioxidant mechanisms can probably prevent $\mathrm{NIHL}^{[5,6]}$.

Drugs from different families have been used for this purpose. Different kinds of statins are currently used as cholesterol-lowering agents, by inhibiting HMG-CoA reductase, though they have other effects on the body independent of this effect known as the pleotropic effects of statins ${ }^{[1,7}$ and 8$]$.

Pravastatin is a member of the drug class of statins, used in combination with diet, exercise, and weight loss for lowering cholesterol and preventing cardiovascular disease $^{[8]}$.

\section{MATERIALS AND METHODS}

Twenty four adult male guinea pigs with average weight 300400- gm were housed in the Medical Research Center Ain Shams University and were kept for seven days before 
the beginning the experiment for acclimatization. They were maintained in standard cages at room temperature and were allowed free access to water and standard chow. All animal procedures were performed in accordance with the guide for the care and use of laboratory animals and approved by the animal ethical committee of the Ain Shams University.

\section{Experimental protocol:}

All animals were divided randomly into three groups: Group I: Control group: This group included 12 animals, further subdivided equally into two subgroups: Subgroup IA: 6 animals received no treatment. Subgroup IB: 6 animals received Pravastatin orally by orogastric tube at a dose of $20 \mathrm{mg} / \mathrm{kg}$ once daily for 6 weeks. Group II: Noise exposed group: 6 animals exposed to noise (70 to $90 \mathrm{~dB}$ ) for 6 hours/day for 6 weeks. Group III: 6 animals exposed to noise (7090- dB) 6 hours/day and given Pravastatin at a dose of $20 \mathrm{mg} / \mathrm{kg}$ once daily for 6 weeks ${ }^{[9]}$.

Pravastatin, trade name Lipostat in the form of yellow colored biconvex tablets (40 mg of Pravastatin sodium), was obtained from SmithKline Beecham Egypt L.L.C. Each tablet was grounded and dissolved in $10 \mathrm{ml}$ distilled water then the solution was shakenuntil it became clear.

\section{Method of noise exposure:}

The experimental groups were exposed to noise produced by two loud speakers (12 Watts) (Model No: AKH 8005, Platinum, China) located at a distance of $10 \mathrm{~cm}$ from the sides of the animals ' cages and driven by a FM radio emitting all the frequencies in the range $30 \mathrm{~Hz}-18$ $\mathrm{kHz}$. All animals were exposed to noise simultaneously at the same session to ensure the same testing environment and the same level of noise exposure. A digital sound level meter (Model No. 3300099, Radio shake, China) was used to set the intensity of sound between 70 to $90 \mathrm{~dB}$ uniformly in the cages ${ }^{[10]}$.

\section{Sample collection}

At the end of the experiment, all animals were sacrificed by cervical dislocation under anesthesia by phenobarbital sodium. The cochleae were dissected from the temporal bone carefully. The specimens were washed with water to remove the debris. A tiny hole at the apex of the cochlear capsule was done by one $\mathrm{ml}$ syringe needle, and gently forcing the fixative using a fine needle to ensure complete infiltration of the cochlea by the proper fixative. The bodies of the dead animals were disposed in the incinerator. The cochleae were subjected to the following histological techniques.

\section{Light microscopic study}

Specimens were fixed and decalcified by using formalin
EDTA for 4 weeks. The solution was changed every day. An ample volume of decalcifying solution was used, at least 3050 - times the volume of tissue ${ }^{[1]}$.

The decalcified specimens were washed and processed for formation of paraffin blocks. Then they were embedded in paraplast. Serial sections about $5 \mu \mathrm{m}$-thick mid-modiolar longitudinal sections were cut and subjected to: H\&E, Toluidine blue stain for Nissl's granules in spiral ganglion and Fontana Masson`s stain for melanin granules ${ }^{[12]}$.

\section{Scanning electron microscopic study}

Cochleae were fixed immediately in $1.5 \%$ glutaraldehyde in phosphate buffered saline (PBS) (pH: 7.4) for two hours at room temperature. Thereafter, gradual dehydration performed in ascending grades of alcohol 10 minutes each followed by one change $1: 1$ absolute and acetone, for 10 minutes and then in acetone. They were then dried using critical point dryer, using liquid carbon dioxide. Microdissection of the cochleae was then carried out by microsurgical scissor and forceps. The specimens were mounted on brass studs using double adhesive tape and coated with $20 \mathrm{~nm}$ layer of gold in a JFC-ion sputter (HEOL, Tokyo, Japan) using sputter coater $\mathrm{SCD} / 0 \mathrm{Y} 15$. Examination of the specimens was done in the Anatomy Department, Ain Shams University, with an XL30 SEM (Philips, Amsterdam, Netherlands) operated at $30 \mathrm{KV}^{[12]}$.

\section{Morphometric and statistical study}

In all groups, randomly chosen five fields/section, in five sections for every guinea pig underwent measurement of the followed parameters at a constant magnification (40x):

- The spiral ganglion neuron surface area, expressed in $\mu \mathrm{m} 2$, was measured in H\&E stained sections.

- The area percentage of Nissl's granules in the spiral ganglion neurons was measured in toluidine blue stained sections.

- The area percentage of melanin granules in the stria vascularis was measured in Fontana Masson`s stained sections.

The measurements were performed using Leica microscope DM 2500 connected to a camera (Leica DFC 295 ) and Leica Q win V3 image analysis software, at the Department of Histology and Cell Biology, Faculty of Medicine, Ain Shams University. The PC was connected to an Olympus XB microscope-Japan.

All values of the morphometric results were expressed as mean \pm SEM. Statistical analysis was carried out using Statistical package for the social science (SPSS), software 
program, version 20 (IBM Corporation, Armonk, North castle, Westchester county, New York, USA). Statistical difference among groups was determined using two-way analysis of variance (ANOVA) followed by post hoc least significance difference (LSD) for comparison between more than two groups $(\mathrm{N}=6)^{[13]}$.

\section{RESULTS}

\section{Group I "Control group"}

Both subgroups IA and IB showed the same histological picture. Examination of H\&E-stained cross sections showed the triangular scala media between the scala vestibuli above and the scala tympani below. It was bounded by the basilar membrane below, the stria vascularis laterally, and the vestibular membrane above. The surface of the basilar membrane in the scala tympani was covered by a thin layer of vascularized connective tissue and elongated epithelial cells. It supports the organ of Corti. The tectorial membrane normally rested on the hair cells of the organ of Corti (Figs. 1 and 2).

The organ of Corti was formed of three rows of outer hair cells (OHC) and one row of inner hair cells (IHC) separated by inner and outer Pillar cells. Pillar cells surrounded the inner tunnel of Corti. OHCs were surrounded by outer phalangeal cells while the IHCs were surrounded by inner phalangeal cells (Fig. 2).

The stria vascularis was formed of three layers: marginal cells, intermediate cells (melanocyte-like cells) and basal cells. The stria vascularis was highly vascularized containing intraepithelial capillaries. Lateral to the stria vascularis, the spiral ligament was formed of a connective tissue containing fibrocytes (Fig. 3).

The spiral ganglion was located within the modiolus containing neurons of the cochlear nerve. The bipolar neurons appeared rounded or polygonal in shape in cross section and showed vesicular nuclei with prominent nucleoli (Fig. 4).

The spiral ganglion neurons were also demonstrated in the toluidine blue-stained sections with their cytoplasm studded with Nissl's granules. The cells showed large pale vesicular nuclei (Fig. 5).

Melanin granules in stria vascularis were stained specifically by Fontana Masson`s stain. They appeared as fine or course granules distributed in the cells of all layers (Fig. 6).

SEM examination of this group showed the cochlea consisted of a spiral tunnel in the temporal bone. The tunnel showed nearly three and half turns as it proceeds from the base of the cochlea to its apex (Fig. 7).
OHCs stereocilia appeared to be arranged in three "V" shaped rows while those of the IHCs were arranged in one linear row. Both of them appeared erect, regular and well organized (Fig. 8).

\section{Group II "Noise exposed group"}

H\&E stained sections of this group showed variable histological changes of both hair cells and supporting cells. Some of the outer hair cells especially those in the 3 rd row and outer phalangeal cells showed vacuolated cytoplasm and pyknotic nuclei. Disrupted Pillar cells were observed (Fig. 9).

Many sections showed cracking of the stria vascularis epithelium. Some intermediate cells appeared vacuolated. An apparent increase of melanin granules was clearly visible. Congested intraepithelial blood capillaries were also seen. Highly vacuolated fibrocytes of the spiral ligament could be detected (Fig. 10 and 11).

Spiral ganglion neurons, in this group, appeared shrunken with eccentric deeply stained nuclei (Fig. 12). This group showed significant decrease $(\mathrm{P}<0.05)$ in the mean surface area of spiral ganglion neurons as compared to the control group (Table 1 and Histogram 1).

Toluidine blue stained sections showed apparent decrease of the cytoplasmic Nissl's granules content compared with control group. Marginated nuclear chromatin was observed (Fig. 13). This group showed highly significant decrease $(\mathrm{P}<0.00)$ in the mean area percentage of Nissl's granules when compared to the control group (Table 1 and Histogram 2).

Fontana Masson`s stained sections showed apparent increase in melanin granules in all layers of stria vascularis (Fig. 14). Highly significant increase $(\mathrm{P}<0.00)$ in the mean area percentage of melanin granules was observed when compared to the control group (Table 1 and Histogram 3).

In SEM examined sections, there were areas of partial and complete loss of stereocilia of both IHCs and $\mathrm{OHCs}$ with extrusion of cellular materials on the reticular lamina. Damage in the form of blebbing (swelling) of a stereocilia of the IHCs was noticed in other sections with marked disarrangement of the remaining stereocilia being collapsed against the reticular lamina (Fig. 15 and 16).

\section{Group III "Drug-treated group"}

Most H\&E-stained sections showed protective effect of Pravastatin on the organ of Corti with apparently 
normal IHCs, OHCs and their surrounding supporting cells (Fig. 17).

Stria vascularis epithelium appeared comparable to control with normal intraepithelial capillaries. Apparently normal spiral ligament and fibrocytes with vesicular nuclei were noticed (Fig. 18).

Almost normal spiral ganglion neurons with their vesicular nuclei were seen compared with the control sections (Fig. 19). There was significant increase $(\mathrm{P}<0.05)$ in the mean surface area of the spiral ganglion neurons when compared to group II while there was a non-significant decrease $(\mathrm{P}>0.05)$ when compared to the control group (Table 1 and Histogram 1).

Toluidine blue-stained sections showed apparently normal structure of the spiral ganglia neurons with Nissl`s granules content comparable to the control group (Fig.
$20)$. Also, there was highly significant increase $(P<0.00)$ in the mean area percentage of Nissl's granules when compared to group II while there was a non-significant $(\mathrm{P}>0.05)$ decrease when compared to the control group (Table 1 and Histogram 2).

Melanin granules content appeared to be decreased in comparison to group IIA in Fontana Masson's stained sections (Fig. 21). There was highly significant decrease $(\mathrm{P}<0.00)$ of mean area percentage of melanin granules when compared to group II while there was non-significant decrease $(\mathrm{P}>0.05)$ when compared to the control group (Table 1 and Histogram 3 ).

SEM examination of cochleae in this group showed apparently normal arranged stereocilia of both outer and inner hair cells, although focal disorganization of stereocilia of IHCs was detected in few sections (Fig. 22).

Table 1: Mean $\pm \mathrm{SD}$ of surface area of spiral ganglion neurons, Nissl`s granules area percentage in spiral ganglion neurons and melanin area percentage in stria vascularis.

\begin{tabular}{lccc}
\hline & $\begin{array}{c}\text { Mean surface area of spiral } \\
\text { ganglion neurons }\left(\mu \mathrm{m}^{2}\right)\end{array}$ & $\begin{array}{c}\text { Mean area percentage } \\
\text { of Nissl`s granules }\end{array}$ & Mean area \% of melanin \\
\hline Subgroup IA & $120.28 \pm 0.310$ & $20.81 \pm 0.454$ & $0.56 \pm 0.196$ \\
Subgroup IB & $119.78 \pm 0.541$ & $20.36 \pm 0.528$ & $0.59 \pm 0.198$ \\
Group II & $115.51 \pm 0.475^{*}$ & $14.49 \pm 0.74^{* *}$ & $6.85 \pm 1.239^{* *}$ \\
Group III & $119.46 \pm 0.415$ & $20.05 \pm 0.457$ & $0.85 \pm 0.263$ \\
\hline
\end{tabular}

*significant change $\mathrm{P}$ value $<0.05$ in group II in comparison to other groups.

$* *$ highly significant change $\mathrm{P}$ value $<0.01$ in group II in comparison to other groups.

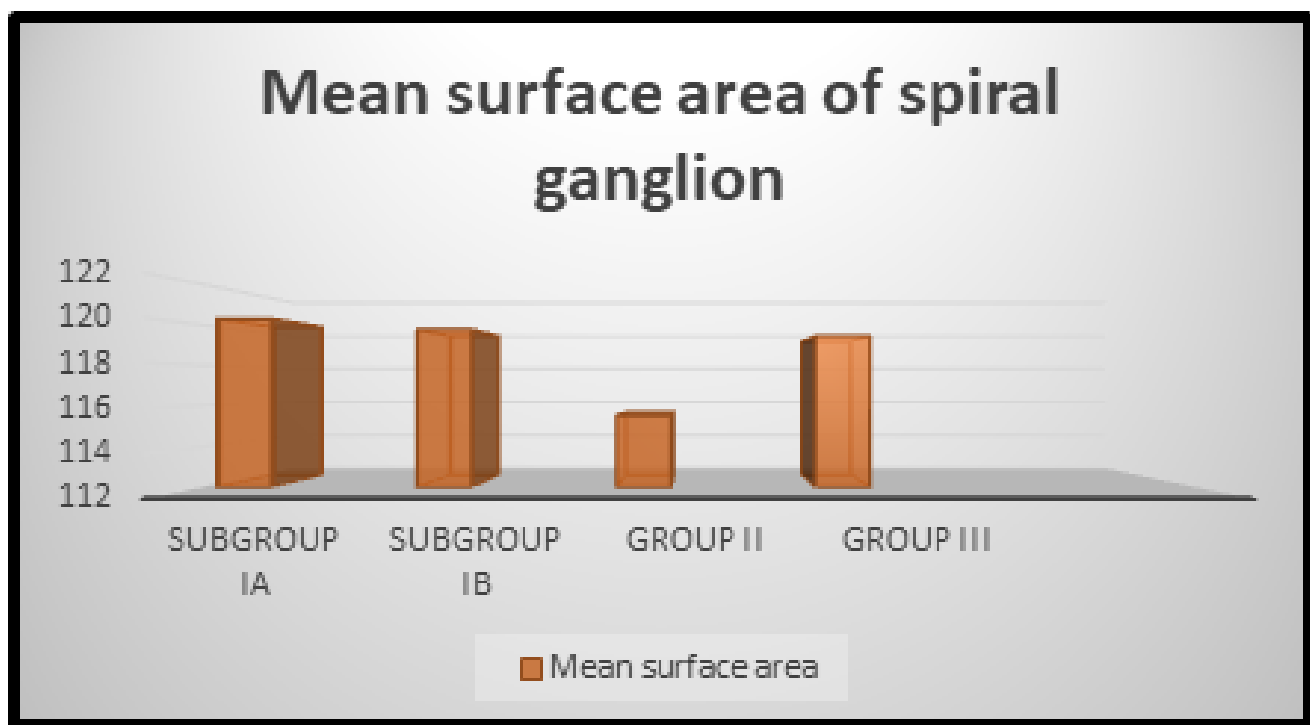

Histogram 1: Mean surface area of spiral ganglion in neurons in high power field in different groups. 


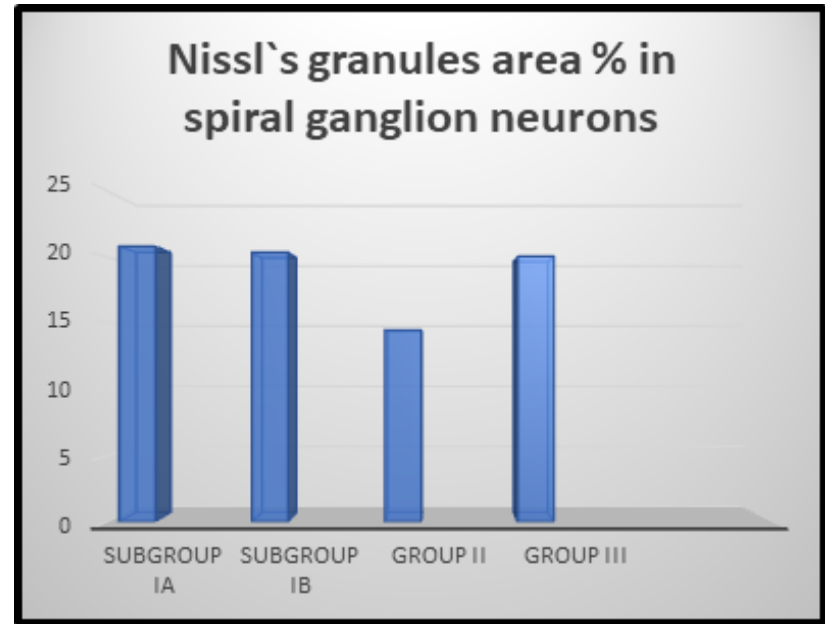

Histogram 2: Mean area percentage of Nissl's granules in spiral ganglion neurons in high power field in different groups.

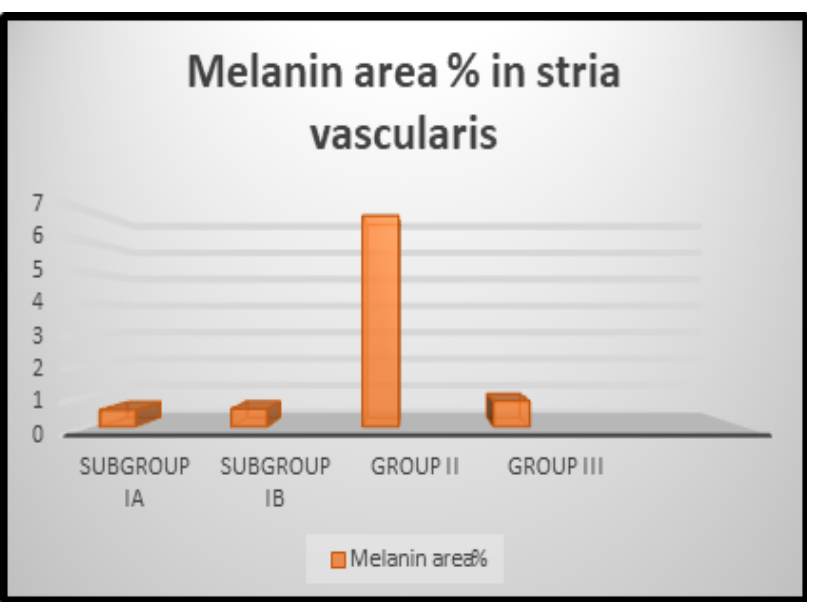

Histogram 3: Melanin area percentage in stria vascularis in high power filed images in different groups.

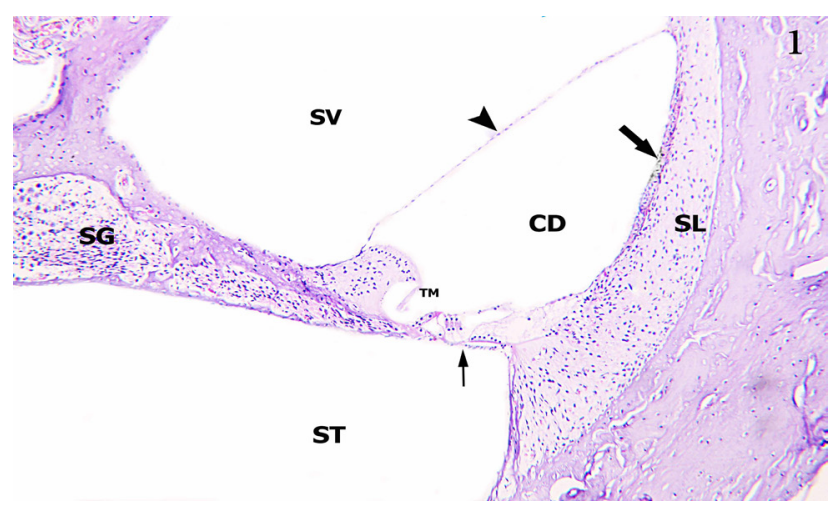

Fig. 1: A photomicrograph showing the cochlear duct (CD) that lie between the scala vestibule (SV) and the scala tympani (ST). The cochlear duct is bounded by the basilar membrane $(\uparrow)$ below, the stria vascularis $(\boldsymbol{M})$ and spiral ligament $(\mathrm{SL})$ on the lateral side, and the vestibular membrane $(\boldsymbol{\Delta})$ above. The organ of Corti rests on the basilar membrane and is overlaid by the tectorial membrane (TM). Notice the spiral ganglion (SG) on the medial side.

(Control group I: H\&E x100)

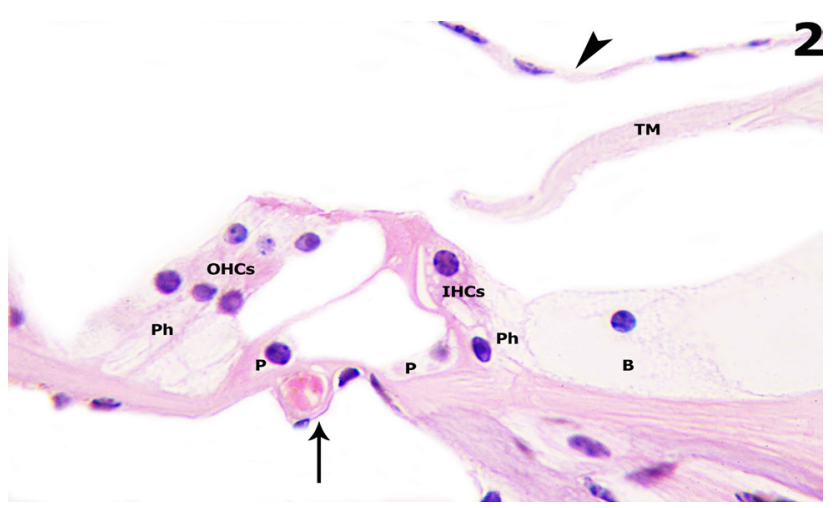

Fig. 2: The organ of Corti is seen resting on the basilar membrane $(\uparrow)$. Three rows of outer hair cells $(\mathrm{OHC})$ and one row of inner hair cells (IHC) with their supporting Phalangeal cells $(\mathrm{Ph})$ are clearly visible. Pillar cells (P) and Border cells (B) can be seen. Notice the Tectorial membrane (TM) and the vestibular membrane ( $\mathbf{\Delta})$.

(Control group I: H\&E x1000)

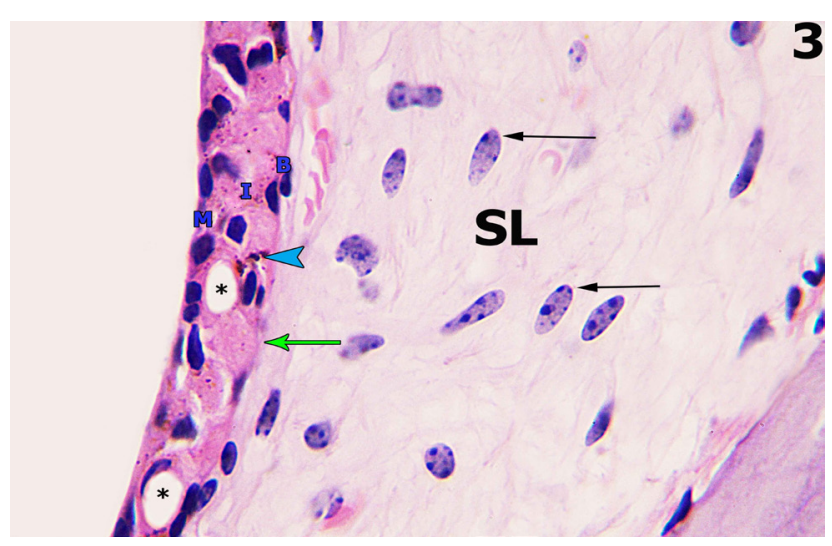

Fig. 3: Stria vascularis epithelium is seen resting on basal lamina $(\rightarrow)$. It is formed of three layers of cells, the marginal $(M)$, intermediate (I) and basal (B) cells. Melanin granules can be seen in all layers of strial epithelium ( $(\mathbf{)}$ ). Intraepithelial blood capillaries are clearly seen $(*)$. Notice the spiral ligament (SL) and fibrocytes with vesicular nuclei $(\rightarrow)$.

(Control group I: H\&E x1000)

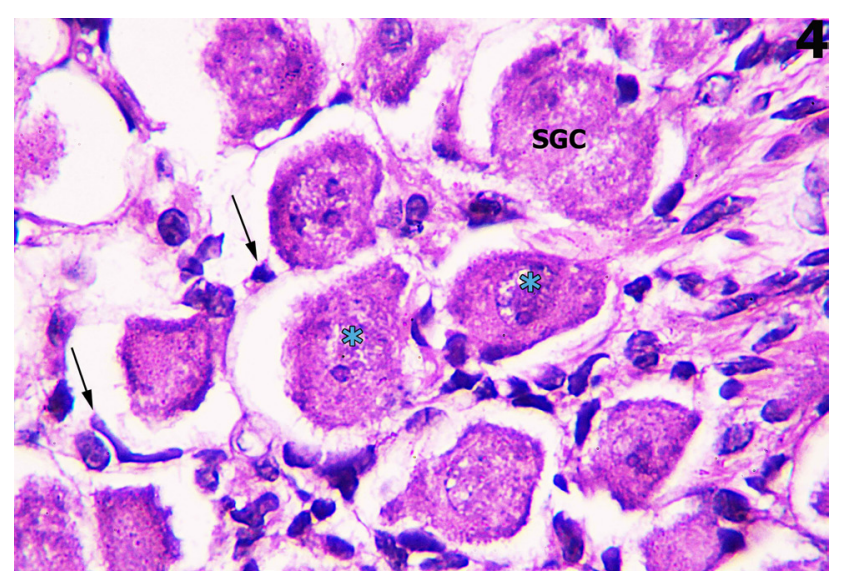

Fig. 4: A photomicrograph showing neurons of spiral ganglion (SGC) and the glial cells $(\uparrow)$. Notice the vesicular nuclei of spiral ganglion cells $(*)$. (Control group I: H\&E x1000) 


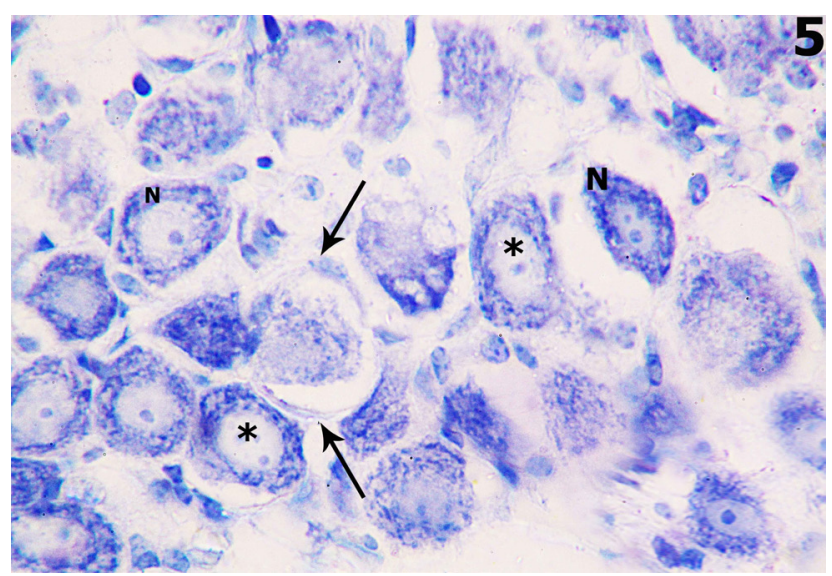

Fig. 5: A photomicrograph showing the densely-packed neurons of spiral ganglion being wrapped by glial cells $(\uparrow)$. The cells have vesicular nuclei $(*)$. Nissl's granules $(\mathrm{N})$ can be seen in the cytoplasm of the neurons as dark basophilic granules.

(Control group I: Toluidine blue x1000)

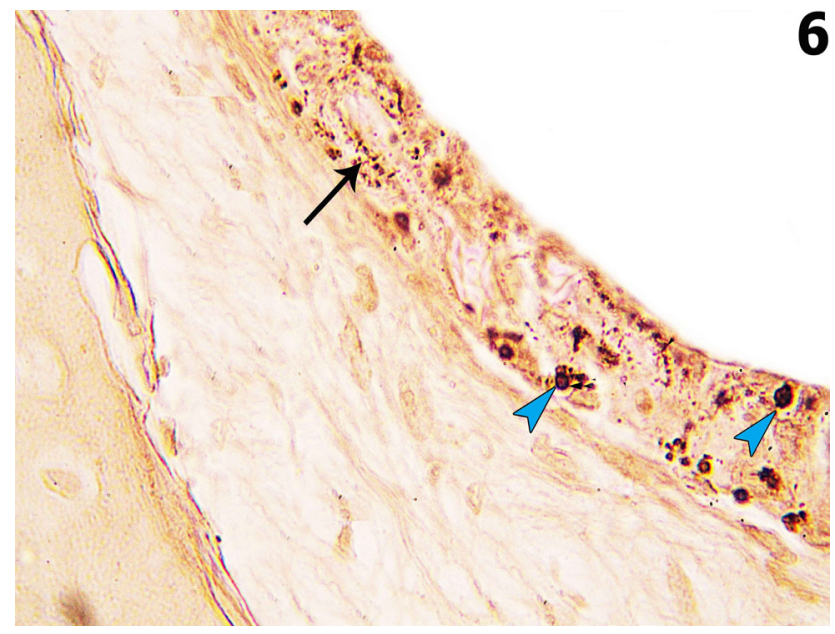

Fig. 6: A photomicrograph showing coarse melanin granules ( $)$ and fine granules $(\uparrow)$ in all layers of stria vascularis. (Control group I: Fontana Masson`s x1000)

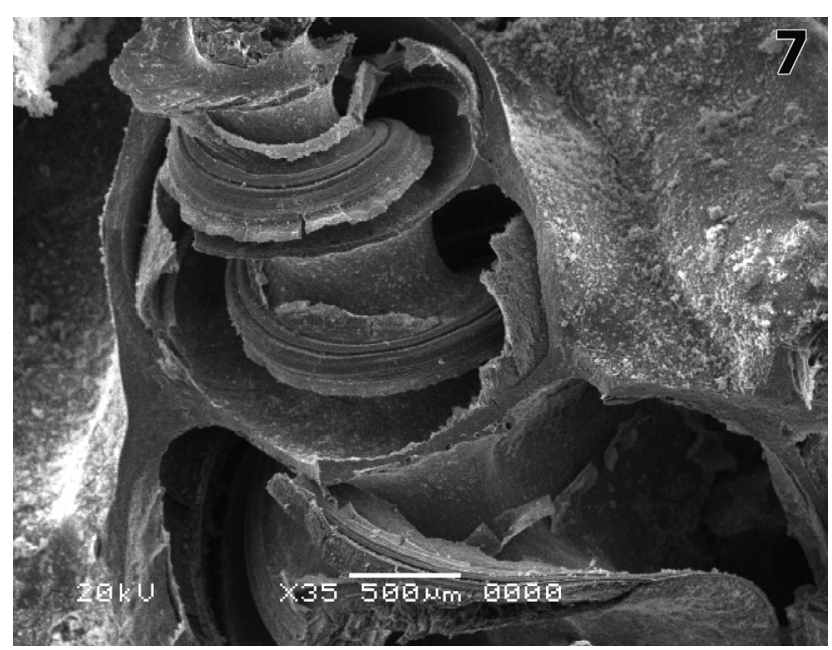

Fig. 7: Scanning electron micrograph showing a panoramic view of the turns of the cochlea of a guinea pig.

(Control group I: SEM x35)

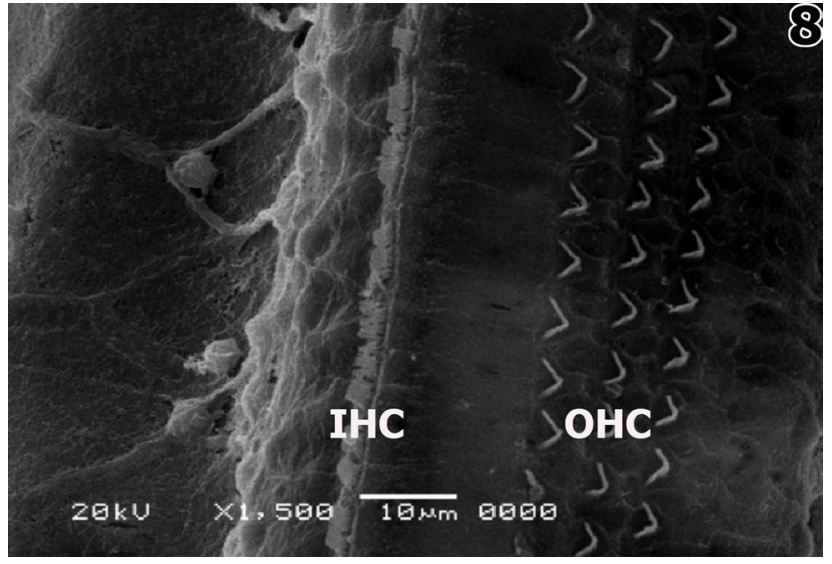

Fig. 8: A scanning electron micrograph showing the uniform regular arrangement of the stereocilia of the inner hair cells (IHC) in a single row and outer hair cells $(\mathrm{OHC})$ in three rows over the reticular lamina (RL). Notice the erect, well organized, regular arrangement of the stereocilia on the apical surface of both inner and outer hair cells.

(Control group I: SEM x1500)

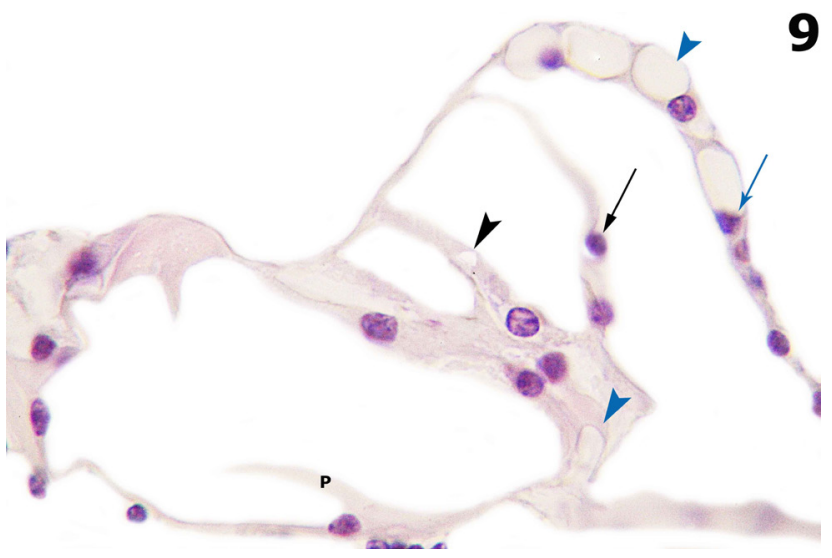

Fig. 9: Condensed nuclei $(\uparrow)$ and vacuolated cytoplasm $(\bullet)$ of outer hair cells are clearly visible. Deeply stained nuclei $(\uparrow)$ and vacuolated cytoplasm ( $)$ of supporting cells can be seen. Notice disrupted Pillar cells (P).

(Subgroup IIA H\&EX1000)

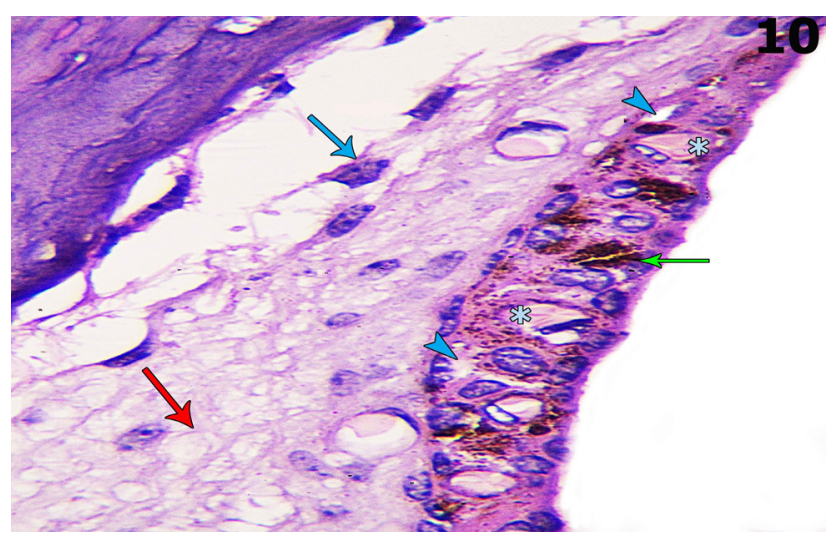

Fig. 10: Vacuolated strial epithelial cells $(\triangleright)$ and Apparent increase of melanin granules is clearly visible $(\rightarrow)$. Congested intraepithelial blood capillaries are seen $(*)$. Deeply stained nuclei of fibrocytes of the spiral ligament can be seen $(\uparrow)$. Also notice the highly vacuolated fibrocytes $(\uparrow)$. Notice the apparent increase in thickness of stria vascularis in comparison to the control group. (Subgroup IIA: H\&E x1000) 


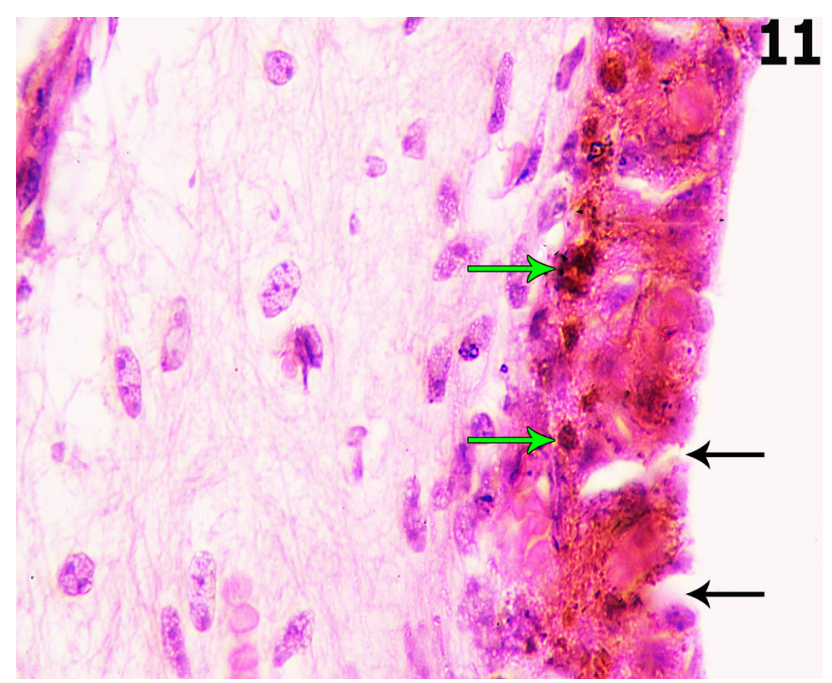

Fig. 11: Cracking of the stria vascularis epithelium $(\uparrow)$ together with apparent increase of melanin granules $(\rightarrow)$ are noticed.

(Subgroup IIA: H\&E x1000)

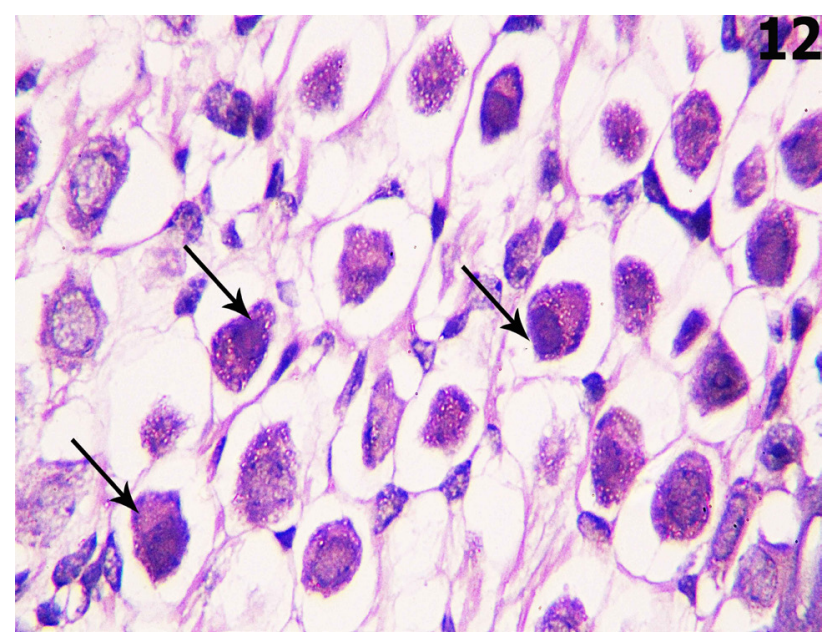

Fig. 12: Apparent decrease in the size of spiral ganglion neurons some deeply stained eccentric nuclei can be seen $(\uparrow)$.

(Subgroup IIa:H\&E x1000)

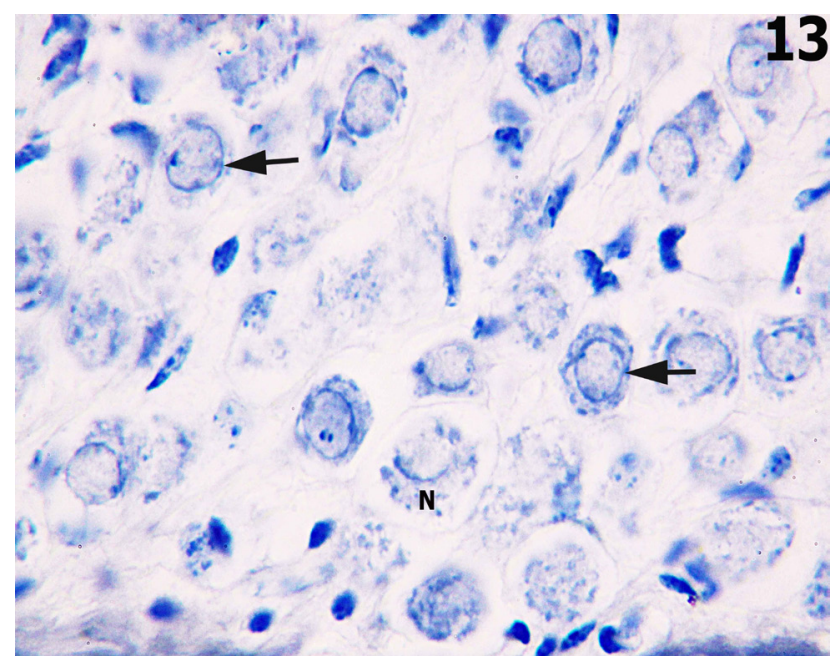

Fig. 13: Marginal nuclear chromatin $(\uparrow)$ and apparent decrease in Nissl's granules content can be noticed (N).

(Subgroup IIA: Toluidine blue x1000)

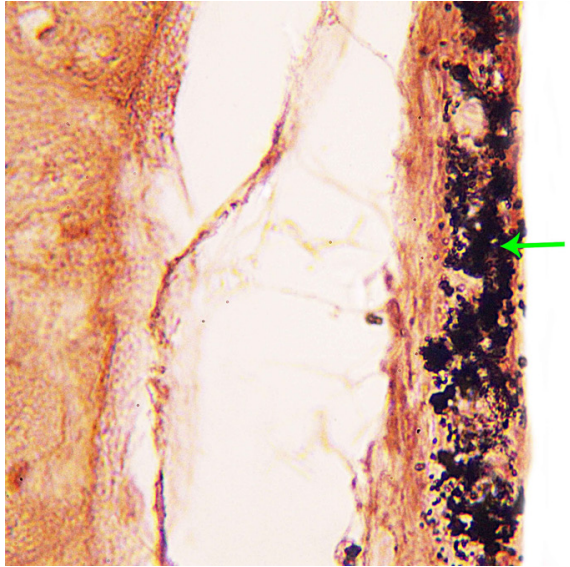

14

Fig. 14: Apparent increase in melanin granules $(\rightarrow)$ in all layers of stria vascularis is seen.

(Subgroup IIA: Fontana Masson`s x1000)

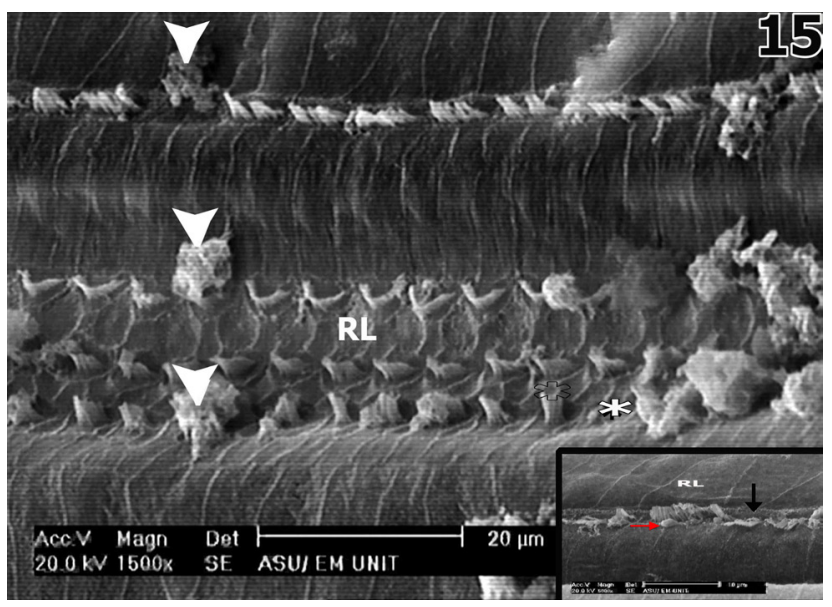

Fig. 15: Scanning electron micrograph showing clearly visible damage in the form of areas of complete loss $(*)$ of stereocilia of both IHCs and OHCs with extrusion of cellular materials $(\nabla)$ on the reticular lamina (RL). Notice the swollen stereocilia $(\uparrow)$ of the IHCs and the disorganized stereocilia ( $\uparrow$ ) (inset).

(Subgroup IIA: SEM x1500)

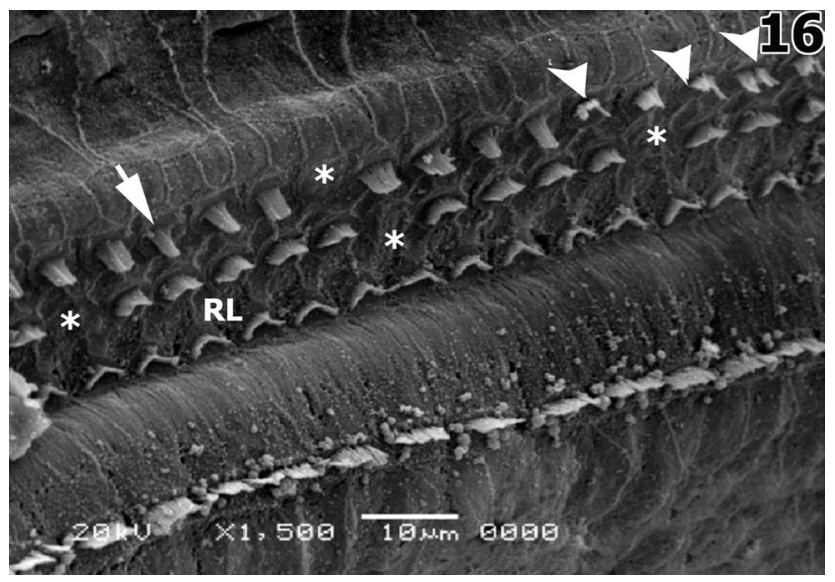

Fig. 16: Scanning electron micrograph showing clearly visible damage in the form of areas of complete loss of stereocilia of the OHCs especially of in the 2 nd and 3 rd rows $(*)$. Also, partial loss of stereocilia of the OHCs in the 3rd row can be seen $(\rightarrow)$ also shortening of some stereocilia can be noticed ( $\triangleright$ ).

(Subgroup IIA: SEM x1500) 


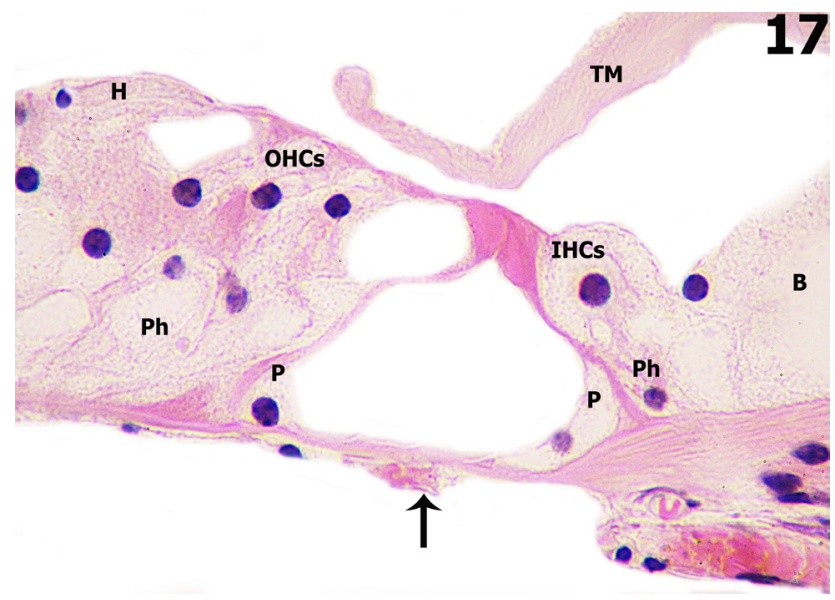

Fig. 17: Normal appearance of the outer (OHCs) and inner hair cells (IHCs) are seen resting on the basilar membrane $(\uparrow)$ and their supporting cells such as Phalangeal cells $(\mathrm{Ph})$, Border cells (B), Hensens cells (H), and Pillar cells (P).

(Subgroup IIB: H\&Ex1000)

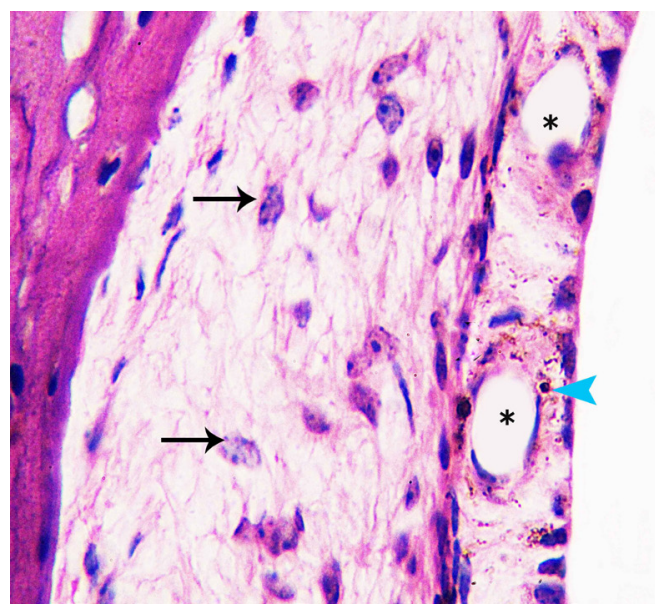

18

Fig. 18: A photomicrograph showing stria vascularis containing melanin granules ( $)$ and showing intraepithelial capillaries $(*)$. Spiral ligament (SL) appear normal. Notice the vesicular nuclei of fibrocytes $(\uparrow)$.

(Subgroup IIB: H\&E x1000)

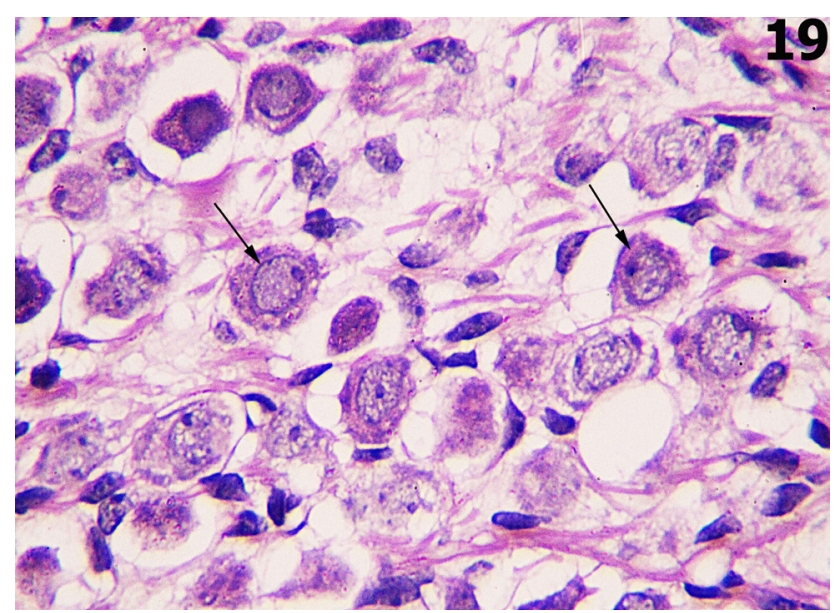

Fig. 19: Almost normal spiral ganglion neurons with their vesicular nuclei ( ) are seen.

(Subgroup IIB: H\&E x1000)

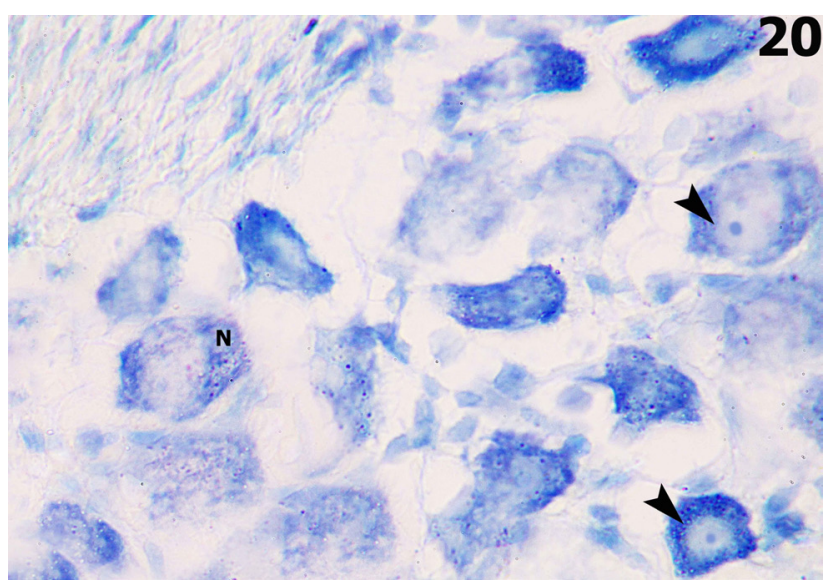

Fig. 20: A photomicrograph showing apparently normal structure of the neurons with vesicular nuclei ( $(\mathbf{)}$ ). The cytoplasm is studded with Nissl's granules (N).

(Subgroup IIB: Toluidine blue x1000)

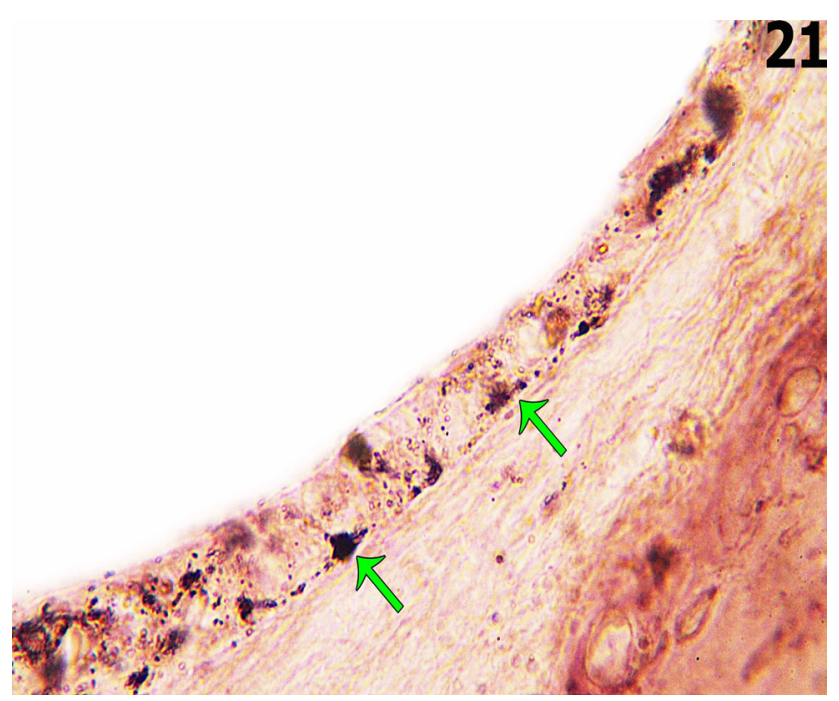

Fig. 21: Apparent decreased melanin granules $(\rightarrow)$ content of stria vascularis compared to subgroup IIa.

(Subgroup IIB: Fontana Masson`s x1000)

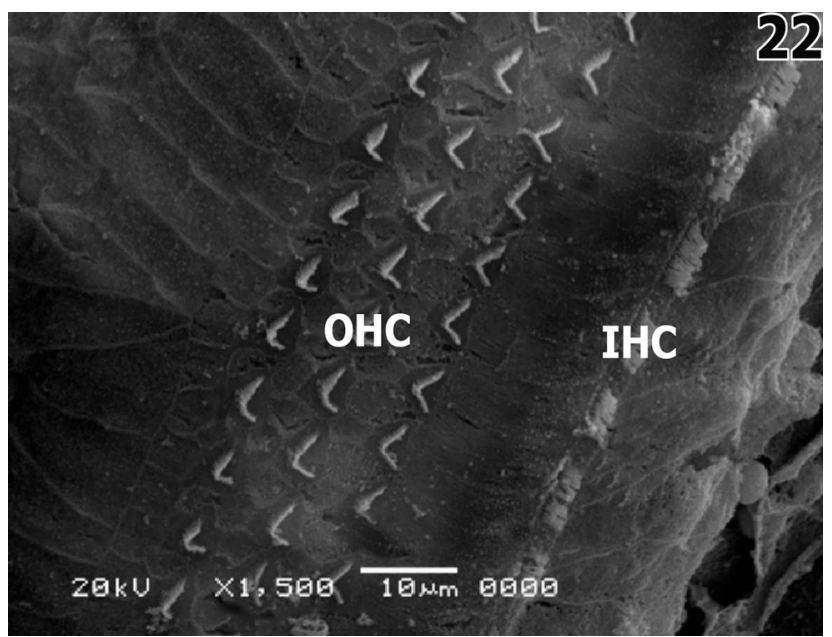

Fig. 22: Scanning electron micrograph showing regular arrangement of most of the stereocilia of both the outer (OHCs) and inner hair cells (IHCs).

(Subgroup IIB: SEM x1500) 


\section{DISCUSSION}

In the present study, adult guinea pigs were exposed daily to sound intensities similar to those faced every day by people during their daily activities which are currently considered moderate levels of sound intensities. The duration of exposure $6 \mathrm{hr} /$ day over 6 weeks, was compatible with the usual working periods ${ }^{[2]}$.

In the current work, we have chosen guinea pigs as the experimental animal because their cochleae are easy to handle for micro dissection purposes because of the size and robustness of their temporal bones. Moreover, guinea pigs' hearing and vestibular systems are very similar to those of humans and that with SEM the guinea pig cochlea has three and half turns and that of the rat has two and half ${ }^{[14,15]}$. Previous investigators noticed the presence of Hansen Cells only in the guinea pigs' turns therefore, guinea pigs were the animals of choice for our study ${ }^{[14,15]}$.

In the current research, H\&E stained sections of guinea pigs of group II showed that both IHCs and OHCs were involved, although the damage tended to predominate in the OHCs especially those in the basal turn. This was in accordance with Gannouni et al. who found $\mathrm{OHCs}$ more sensitive to a variety of noxious influences, including drug toxicity and acoustic trauma, notably after exposure to moderate intensity noise $\mathrm{e}^{[2]}$

Vacuolated OHCs as well as pyknotic nuclei, which are more in the 3 rd row of cells with vacuolated supporting cells and disrupted Pillar cells, were obvious in this group consistent with MoussaviNajarkola et al. ${ }^{[16]}$.

Besides, our SEM findings confirmed these results whereas, areas of complete loss of stereocilia of the OHCs, extrusion of cellular materials in scala media, disorganized arrangement, and swelling and collapsed (bending) stereocilia of IHCs against the reticular lamina appeared. Similarly, other authors ${ }^{[17]}$ observed extensive damage, loss of stereocilia and holes in the apical membranes of OHCs and IHCs originated from the bursting of blebs formed at the apical pole of the stressed hair cells to release cellular material into the endolymphatic compartment. They observed these findings by SEM and TEM examination after acoustic trauma.

This supports the idea that massive apical exocytosis occurred in the hair cells in order to evacuate an excess of metabolic waste that had accumulated in the cell body during the sound exposure ${ }^{[2]}$.

Moreover, noise exposure causes permanent loss of hair cell stereocilia with apparent fracture of the rootlet structures and destruction of the sensory cells, which are replaced by nonfunctioning scar tissue ${ }^{[18]}$. This explains the stereociliary damage in the present study.

On the other hand, Chuang et al ${ }^{[1]}$ stated the occurrence of NIHL by auditory brain stem response (ABR) testing following moderate intensity noise although there was no deletion or displacement of stereocilia and normal morphology of cochlear hair cells was observed.

Some investigators[19-21] explained that a strong reason for noise induced cochlear HCs dysfunction and damage to organ of Corti is based on oxidative stress mechanisms and metabolic exhaustion. This is believed to occur when toxic waste products as free radicals, including reactive oxygen species (ROS) or reactive nitrogen species, are formed after cochlear cells are stressed by reduction in cochlear blood flow, excessive and toxic levels of neurotransmitters like glutamate, change in calcium balances in the cell, and other stress related changes that are induced by noise. They reported the presence of ROS in the cells following noise exposure which persist for 7-10 days after, spreading from the basal region of organ of Corti to the apical turns.

Noise induced cochlear ROS endanger hair cells intrinsic antioxidant system as glutathione (GSH) that is found to be the powerful natural antioxidant glutathione peroxidase system in cochlear hair cells. Depletion of cochlear hair cells GSH in organ of Corti due to exposure to noise can cause more susceptibility to hearing $\operatorname{loss}^{[22 \text { and } 23]}$.

ROS can cause damage by reacting with DNA, proteins, cytosolic molecules, cell surface receptors and breaking down membrane lipids.ROS generation also leads to inflammation and production of proinflammatory cytokines Interleukin 6 and tumor necrosis factor alpha ${ }^{[24]}$.

The biological basis of NIHL is metabolic changes resulting from hypoxia caused by noise induced capillary vasoconstriction and spasm of spiral modular artery (SMA) which can lead to ischemia. Spiral modular artery supports the inner ear's circulation. Increase in intracellular calcium levels.

due to noise over stimulation causes increased resistance in the vascular smooth muscle cells that can lead to cochlear damage due to the vasoconstriction of $\mathrm{SMA}^{[17]}$.

Our research showed excessive damage of the spiral ganglion neurons in the form of pyknotic 
eccentric nuclei, margination of nuclear chromatin and shrinkage of their cell bodies following noise exposure. In context, other investigators ${ }^{[2,25}$ and 26] reported marked loss of spiral ganglion cells, marked decrease in their density, marked retraction of the cell body and irreversible ultrastructural changes of the neurons, their afferent nerve endings and cochlear nerve although there was no damage to IHCs and OHCs.

Toluidine blue stained sections of this group showed decreased Nissl's granules content in spiral ganglion neurons consistent with Ajibade et al. ${ }^{[27]}$, who observed chromatolytic changes in damaged neurons in the form of reduced staining.

The present study showed structural changes in the stria vascularis epithelium like intermediate cells vacuolations, cracking in the epithelium and congested intrastrial blood capillaries. Degenerated fibrocytes in the spiral ligament with pyknotic nuclei were noticed. This was consistent with the study conducted by some authors ${ }^{[28 \text { and } 29]}$ who explained that this strial and spiral ligament changes might be due to excessive $\mathrm{K}$ influx through transduction channels or excessive production of glutamate or its analogs by hair cells induced by noise exposure or dysfunction of $\mathrm{Na}+\mathrm{K}+$ pump or gap junction of strial epithelium.

Our study showed marked increase in melanin granules content of stria vascularis following exposure to noise and this was in accordance with Wassif and El Begermy ${ }^{[30]}$ suggesting that melanin bearing cells of the ear are capable of markedly increase activity in response to stressful conditions.

Others explained that melanin has free radical scavenging properties and therefore, it could act as an antioxidant during cochlear injury induced by oxidative stress in the presbycusis and NIHL ${ }^{[31}$ and 32$]$.

In group III, H\&E stained sections showed apparently normal OHCs and IHCs and their supporting cells. These results were also confirmed by the findings of the SEM that showed almost normal, erect and well organized stereocilia of both $\mathrm{OHCs}$ and IHCs.

In agreement, previous researchers ${ }^{[3,8,33 \text { and } 34]}$ found drug reduced hair cell death in the cochlea after noise exposure. They also showed that this attenuation was caused by inhibition of nicotine amide adenine dinucleotide phosphate (NADPH) oxidase complex formation which is suggested to generate reactive oxygen species (ROS) after excessive noise. They also suggested that statins reduce endothelial inflammatory effects that influence the blood supply to the inner ear. However, others ${ }^{[35]}$ failed to find a statistically significance NIHL protective effect of Pravastatin.

In this regards, Adams et al. came to the conclusion that statins might also attenuate inflammatory responses in inner ear ${ }^{[36]}$. Statins are able to inhibit factors which are involved in the activation of nuclear factor beta (NFB) and controls many genes involved in inflammation. These inflammatory mediators are produced by fibrocytes following noise exposure.

In the present study, (group III) showed normal stria vascularis epithelium and normal intraepithelial blood capillaries. It also showed normal melanin content of stria vascularis comparable to the control group. This could be explained by the well-known vascular protective effects of statins mediated by regulating endothelial nitric oxide synthase expression and ROS levels ${ }^{[8]}$. In context, Mihos et al and Blum et al stated that ischemia/reperfusion injury derived from the stria vascularis has been also proposed as one of potential mechanisms for NIHL and accordingly, statins may also affect the stria vascularis, thereby attenuating ischemia/reperfusion injury ${ }^{[37}$ and 38$]$.

Moreover, Other authors ${ }^{[39]}$ pravastatin attenuated 4-HNE expression, which is a phospholipid membrane peroxidation product generated by the reaction of free radicals in the plasma membrane by acoustic overstimulation. Futhermore, the preventive effect of Pravastatin on NIHL may be associated with attenuation of excessive ROS.

In the present study, spiral ganglion neurons in group III were found to be near normal in appearance with vesicular nuclei and slightly retracted bodies with apparently normal Nissl's granules content. In 2016, Whitlon Donna proved that statins induced increase in neurite length and protected the nerve fibers from degeneration induced by noise exposure ${ }^{[40]}$.

\section{CONCLUSION}

Exposure to moderate intensity noise caused damaging effects on the structure of the cochlea of guinea pig that could be ameliorated with Pravastatin treatment.

\section{CONFLICT OF INTEREST}

There are no conflicts of interest.

\section{REFERENCES}

1. Chuang S., Lei S., Xuejun J., Shiming Y. and Ke L.(2014). Effects of Moderate Noise Exposure on Hearing Function in C57BL/6J Mice. Journal of Otology 9, 81- 85. 
2. Gannouni N., Lenoir M., Ben Rhouma K., El May M., Tebourbi O., Puel L. and Mhamdi A.(2015). Cochlear neuropathy in the rat exposed for a long period to moderate-intensity noises. Journal of Neuroscience Research 93, 848 -858.

3. Jahani L., Mehrparvar A., Esmailidehaj M., Rezvani M., Moghbelolhossein B. and Razmjooei Z.(2016). The Effect of Atorvastatin on Preventing Noise-Induced Hearing Loss: An Experimental Study. The international journal of occupational and environmental medicine 7, 627 -615 - 621.

4. Mehrparvar H., Mirmohammadi J., Hashemi H., Davari H., Mostaghaci M., Mollasadeghi A. and Zare Z.(2015). Concurrent effect of noise exposure and smoking on extended high-frequency puretone thresholds. International journal of audiology 54, 5, 301- 307.

5. Kopke R., Slade D., Jackson R., Hammill T., Fausti S., Lonsbury-Martin B., Sanderson A., Dreisbach L., Rabinowitz P. and Torre P.(2015). Efficacy and safety of $\mathrm{N}$-acetylcysteine in prevention of noise induced hearing loss: A randomized clinical trial. Hearing research 323, 40- 50.

6. Oishi N. and Schacht J.(2011). Emerging treatments for noise-induced hearing loss. Expert opinion on emerging drugs 16, 235- 245.

7. Ersoy A., Koc R., Sahin S., Duzgun U., Acar B. and Ilhan A.(2014). Possible effects of rosuvastatin on noise-induced oxidative stress in rat brain. Noise and Health 16, 18.

8. Park J., Kim S., Park K., Choung Y., Jou I. and Park S.(2012). Pravastatin attenuates noiseinduced cochlear injury in mice. Neuroscience 208, 123- 132.

9. Madsen C., Janovitz E., Zhang R., NguyenTran V., Ryan C., Yin X., Monshizadegan H., Chang M., D'Arienzo C. and Scheer S.(2008). The guinea pig as a preclinical model for demonstrating the efficacy and safety of statins. Journal of Pharmacologyand Experimental Therapeutics 324, 576- 586.

10. Lenzi P., Frenzilli G., Gesi M., Ferrucci M., Lazzeri G., Fornai F. and Nigro M.(2003). DNA damage associated with ultrastructural alterations in rat myocardium after loud noise exposure. Environmental health perspectives 111, 467.

11. Bancroft D. and Cook C.(1994). Manual of histological techniques and their diagnostic application. Churchill Livingstone.
12. Bancroft D. and Gamble M.(2008). Theory and practice of histological techniques. Elsevier Health Sciences.

13. Goldstone L. (1983). Understanding medical statistics. William-Heinemann Medical Books Ltd.: London.

14. Albuquerque S., Rossato, M., Oliveira J. and Hyppolito M. (2009). Conhecimento da anatomia da orelha de cobaias e ratos e sua aplicação na pesquisa otológica básica. Revista Brasileira de Otorrinolaringologia 75, $43-49$.

15. De Oliveira J.(1989). Audiovestibular toxicity of drugs. CRC Press.

16. Moussavi-Najarkola S., Khavanin A., Mirzaei R., Salehnia M., Muhammadnejad A. and Akbari M.(2012). Noise-induced outer hair cells' dysfunction and cochlear damage in rabbits. Iranian Red Crescent Medical Journal 14, 647- 656.

17. Kaymakçı M., Acar M., Burukoglu D., Kutlu M., Shojaolsadati P., Cingi C. and Muluk B.(2015). The Potential Protective Effects of 2-aminoethyl Diphenylborinate against Inner Ear Acoustic Trauma: Experimental Study Using Transmission and Scanning Electron Microscopy. The journal of international advanced otology 11, 1- 5.

18. Chen D. and Fechter D.(2003). The relationship between noise-induced hearing loss and hair cell loss in rats. Hearing research 177, 81 -90.

19. Chung S., Chu I. and Cullen R.(2012). Hearing effects from intermittent and continuous noise exposure in a study of Korean factory workers and firefighters. BMC public health 12, 87.

20. Wong C. and Ryan A.(2015). Mechanisms of sensorineural cell damage, death and survival in the cochlea. Aging, neurogenesis and neuroinflammation in hearing loss and protection, 7 .

21. Shim J.(2015). Noise-induced hearing loss. Hanyang Medical Reviews 35, 8491-.

22. Honkura Y., Matsuo H., Murakami S., Sakiyama M., Mizutari K., Shiotani A., Yamamoto M., Morita I., Shinomiya N. and Kawase T. (2016). $\mathrm{Nrf} 2$ is a key target for prevention of noise-induced hearing loss by reducing oxidative damage of cochlea. Scientific reports 6 .

23. Ferrite S. and Santana V.(2005). Joint effects of 
smoking, noise exposure and age on hearing loss. Occupational medicine 55, 4853-

24. Wakabayashi K., Fujioka M., Kanzaki S., Okano J., Shibata S., Yamashita D., Masuda M., Mihara M., Ohsugi Y., Ogawa K., 2010. Blockade of interleukin-6 signaling suppressed cochlear inflammatory response and improved hearing impairment in noise-damaged mice cochlea. Neuroscience research 66, 345- 352.

25. Hellier W., Wagstaff S., O'leary S. and Shepherd R.(2002). Functional and morphological response of the stria vascularis following a sensorineural hearing loss. Hearing research 172, 127- 136.

26. Kujawa G. andLiberman C.(2009). Adding insult to injury: cochlear nerve degeneration after "temporary" noise-induced hearing loss. Journal of Neuroscience 29, 14077- 14085.

27. Ajibade A., Adeeyo A., Ofusori A., Adenowo K., Ishola O., Ashamu A. and Nwangwu C.(2009). Microstructural observations on Nissl substances in the cerebellar cortex of adult Wistar rats following quinine administration. Tropical Journal of Pharmaceutical Research 8.

28. Ohlemiller K., Rosen D. and Gagnon P.(2010). A major effect QTL on chromosome 18 for noise injury to the mouse cochlear lateral wall. Hearing research 260, 47- 53 .

29. Morizane, I., Hakuba, N., Shimizu, Y., Shinomori, Y., Fujita, K., Yoshida, T., Shudou, M. and Gyo, K.(2005). Transient cochlear ischemia and its effects on the stria vascularis. Neuroreport 16, 799-802.

30. Wassif G. and El Begermy M.(2008). Age-Related Changes of the Cochlear Lateral Wall (Stria Vascularis) in the Guinea Pigs: An Ultrastructural Study.

31. Samson J., Wiktorek-Smagur A., Politanski P., Rajkowska E., Pawlaczyk-Luszczynska M., Dudarewicz A., Sha H., Schacht J. and Sliwinska-Kowalska M.(2008). Noise-induced time-dependent changes in oxidative stress in the mouse cochlea and attenuation by D-methionine. Neuroscience 152, 146- 150.
32. Ohlemiller K., Rice R., Lett J. and Gagnon P.(2009). Absence of strial melanin coincides with age-associated marginal cell loss and endocochlear potential decline. Hearing research 249, 1- 14.

33. Koc R., Ersoy A., Ilhan A., Erken H. and Sahın S.(2015). Is rosuvastatin protective against on noise-induced oxidative stress in rat serum? Noise and health 17, 11.

34. Gopinath B., Flood V.M., Teber E., McMahon M. and Mitchell P.(2011). Dietary intake of cholesterol is positively associated and use of cholesterollowering medication is negatively associated with prevalent age-related hearing loss. The Journal of nutrition 141, 1355- 1361.

35. Sanders M.(2012). Protective effect of systemic administration of Pravastatin against noiseinduced hearing loss In the fischer 344/nhsd rat substrain. The Ohio State University.

36. Adams J., Seed B., Lu N., Landry A. and Xavier J.(2009). Selective activation of nuclear factor kappa B in the cochlea by sensory and inflammatory stress. Neuroscience 160, 530 -539.

37. Mihos G., Salas M. and Santana O.(2010). The pleiotropic effects of the hydroxy-methyl-glutarylCoA reductase inhibitors in cardiovascular disease: a comprehensive review. Cardiology in review 18, $298-304$.

38. Blum A. and Shamburek R.(2009). The pleiotropic effects of statins on endothelial function, vascular inflammation, immunomodulation and thrombogenesis. Atherosclerosis 203, 325 -330.

39. Tanaka S., Tabuchi K., Hoshino T., Murashita H., Tsuji S. and Hara A.(2010). Protective effects of exogenous GM-1 ganglioside on acoustic injury of the mouse cochlea. Neuroscience letters 473, 237- 241.

40. Whitlon Donna S.(2016): Drug discovery for hearing loss: Phenotypic screening of chemical compounds on primary cultures of the spiral ganglion. Hearing Research 15-. http://dx.doi. org/10.1016/j.heares.2016.07.019. 0378 -5955/C 2016 Published by Elsevier B.V. 


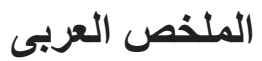

\section{تاثير التعرض للضوضاء متوسطة الشدة على قوقعة ذكر الخنزير الغيني البالغ و الاور الوقائى

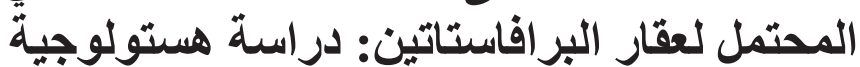

\author{
سوزي حنفي ابراهيم، هاني كمال كامل، عزه عبد المنعم عطيه، هند فريد السيد
}

\author{
قسم الههتولوجيا وبيولوجيا الخليةـ كلية الطب- جامعة عين شمس، القاهرة، مصر
}

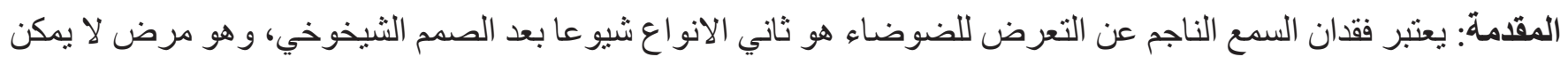

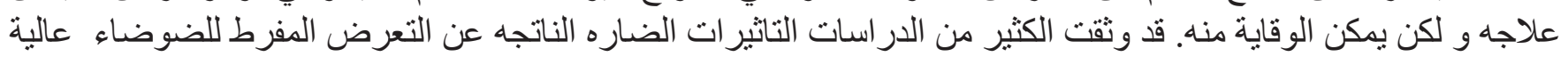

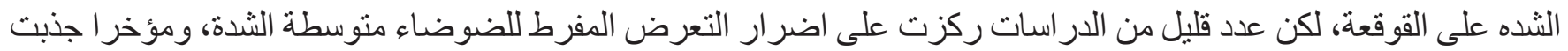

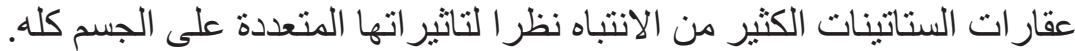

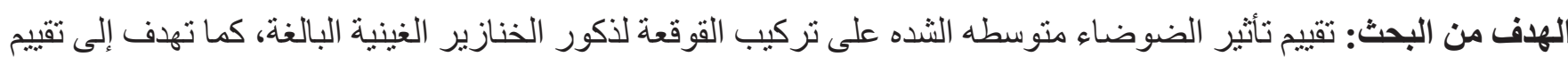
الدور الوقائي المحتمل لعقار البر افاستاتين.

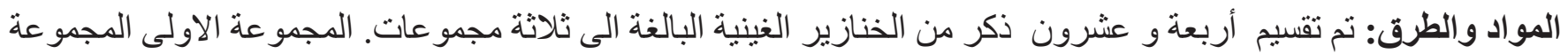

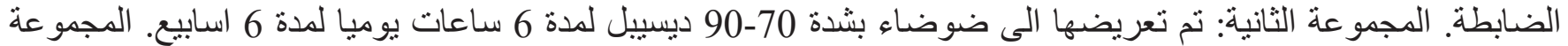

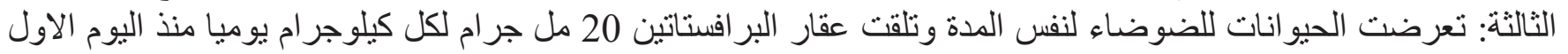
للتعرض للضوضاء ولمدة 6 اسابيع.

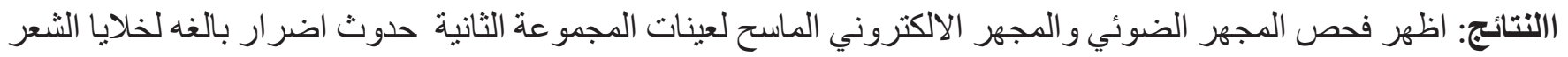

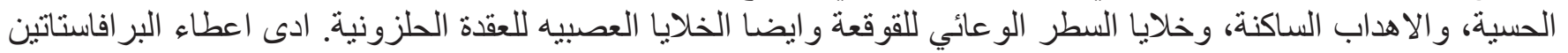

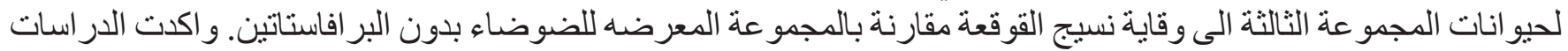
الاحصائيه و المورفومترية هذه النتائج.

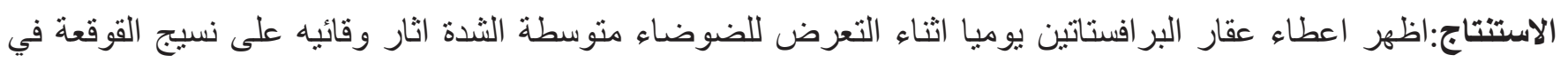
الخنزير الغيني. 